\section{Beneficial Effect of Portacaval Shunt on Cardiac Contractility in Dogs}

\author{
Pallab K. Ganguly* \\ College of Medicine and Medical Sciences, Arabian Gulf Uni- \\ versity, P.O. Box 22979, Manama, Bahrain \\ (Received September 27, 2000; Accepted November 4, 2000)
}

Despite advances in cardiovascular medicine, the endogenous mechanisms responsible for positive inotropic state of the heart is poorly understood. We have assessed surgical transposition of the portal vein (portacaval shunt) as a procedure providing total systemic delivery of portal venous effluent in six dogs. The animals recovered rapidly from the surgery maintaining euglycemia. Four days after surgery the serum enzymes such as alkaline phosphatase, alanine aminotransferase and gamma glutamyl transferase returned to normal values, whereas all the animals had significantly higher values of urine volume and left ventricular $\mathrm{dP} / \mathrm{dt}$. Pre and postoperative left ventricular pressure was unchanged. Our results indicate that portacaval shunt plays an endogenous role in the positive inotropic state of the heart, and suggest that this surgical procedure may provide an insight into its beneficial role in heart failure.

Key words — Portacaval shunt, myocardial contractility, plasma insulin, heart failure

\section{INTRODUCTION}

The gut has many peptides which play a major role in cardiac physiology. ${ }^{1,2)}$ However, the functions of the gut peptides are limited by their entry into the liver, which plays a crucial role in metabolism. Their systemic effects thus may be compromised, confounding interpretation. With systemic diversion of portal venous effluent achieved by endto-side portacaval anastomosis, gut peptides including pancreatic hormones can directly act on cardiac

*To whom correspondence should be addressed: College of Medicine \& Medical Sciences, Arabian Gulf University, P.O. Box 22979, Manama, Bahrain. Tel.: +973-239711; Fax: +973271090; E-mail: p215@batelco.com.bh muscle and can enhance the inotropic state of the heart. ${ }^{3)}$ Accordingly, the experiments were carried out to examine the effect of portacaval shunt on cardiac contractility in dogs. As a preliminary study, the experiments were restricted to the control animals and the various parameters of the pre and postoperative surgery were compared. Our results suggest that portacaval shunt plays an endogenous role in the positive inotropic state of the heart.

\section{MATERIAL AND METHODS}

Animals and Operation - Six mongrel dogs weighing $16-20 \mathrm{~kg}$ were used in this study. The animals were sedated with xylazine $(0.3 \mathrm{mg} / \mathrm{kg}$, im). General anesthesia was maintained with halothane $\left(1.0-2.0 \mathrm{vol} / 100 \mathrm{ml}\right.$ in $\left.\mathrm{O}_{2}\right)$. The dogs were ventilated with a respirator and laporatomy was performed. An end-to-side portacaval shunt was carried out in each dog as described previously. ${ }^{4)}$ The dogs were given standard medical therapy with i.v. glucose and fluids and were observed and monitored in their cages with frequent measurements of hematological and biochemical parameters for four days. Assay — Blood alkaline phosphatase, alanine aminotransferase, gamma glutamyl transferase and bilirubin were measured by computer-assisted vet scan (California, U.S.A.). The hemodynamic data were recorded on a direct-writing oscillograph. Left ventricular pressure and $\mathrm{dP} / \mathrm{dt}$ were obtained as described earlier. ${ }^{5)}$ Insulin and glucagon were measured by radioimmunoassay.

\section{RESULTS AND DISCUSSION}

The effect of portacaval shunt on blood biochemistry is shown in Tables 1 and 2. Table 1 shows the effect of portacaval shunt on the blood level of alkaline phosphatase, alanine aminotransferase, gamma glutamyl transferase and bilirubin. Although these biochemical parameters were elevated following surgery, the levels were normal after 4 days. Table 2 shows the level of insulin, glucagon and glucose following portacaval shunt in dogs. Both insulin and glucagon levels were increased and the animals remained euglycemic throughout the experiments.

The effect of portacaval shunt on hemodynamic 
Table 1. Effect of Portacaval Shunt on Blood Biochemistry in Dogs

\begin{tabular}{|c|c|c|c|c|c|}
\hline \multicolumn{6}{|c|}{ P-C Shunt } \\
\hline & Before & & & After & \\
\hline & $0 \mathrm{hr}$ & $5 \mathrm{hr}$ & $24 \mathrm{hr}$ & 2 days & 4 days \\
\hline Alkaline phosphatase (U/L) & $58 \pm$ & $62 \pm 6$ & $110 \pm 16^{*}$ & $80 \pm 8^{*}$ & $68 \pm 12$ \\
\hline Alanine aminotransferase (U/L) & $205 \pm 22$ & $280 \pm 16^{*}$ & $400 \pm 25^{*}$ & $350 \pm 11^{*}$ & $180 \pm 16$ \\
\hline Gamma glutamyltransferase (U/L) & $5.0 \pm \quad 0.6$ & $6.3 \pm \quad 0.5$ & $8.4 \pm \quad 1.0$ & $8.0 \pm \quad 0.8$ & $5.2 \pm \quad 0.7$ \\
\hline Bilirubin $(\mu \mathrm{mol} / \mathrm{L})$ & $7.3 \pm$ & $8.1 \pm$ & $8.2 \pm$ & $7.5 \pm$ & $7.4 \pm$ \\
\hline
\end{tabular}

${ }^{*} p<0.05$ based on 6 experiments.

Table 2. Effect of Portacaval Shunt on Blood Biochemistry in Dogs

\begin{tabular}{lrrrr}
\hline \multicolumn{3}{c}{ P-C Shunt } \\
\hline \hline \multicolumn{1}{c}{ Before } & \multicolumn{1}{c}{ After } \\
\hline Insulin $(\mu \mathrm{U} / \mathrm{ml})$ & $15 \pm$ & 1 & $28 \pm$ & $1^{*}$ \\
Glucagon $(\mathrm{pg} / \mathrm{ml})$ & $160 \pm$ & 12 & $362 \pm$ & $16^{*}$ \\
Glucose $(\mathrm{mg} / \mathrm{dl})$ & $95 \pm$ & 5 & $101 \pm$ & 6 \\
\hline
\end{tabular}

${ }^{*} p<0.05$ based on 6 experiments

Table 3. Effect of Portacaval Shunt on Hemodynamic Parameters in Dogs

\begin{tabular}{lrrrr}
\multicolumn{5}{c}{ P-C Shunt } \\
\hline & Before & \multicolumn{3}{c}{ After } \\
\hline \hline $\begin{array}{c}\text { Left ventricular systolic } \\
\text { pressure (mmHg) }\end{array}$ & $114 \pm$ & 4 & $118 \pm$ & 5 \\
Left ventricular end & & & & \\
$\quad$ diastolic pressure (mmHg) & & 1 & $8 \pm$ & 1 \\
Left ventricular dP/dt & $2862 \pm$ & 130 & $3925 \pm$ & $124^{*}$ \\
$\quad(\mathrm{mmHg} / \mathrm{S})$ & & & & \\
Hear rate (beat/min) & $86 \pm$ & 5 & $102 \pm$ & $4^{*}$ \\
Urine volume (ml/day) & $340 \pm$ & 50 & $800 \pm$ & $60^{*}$ \\
\hline$* p<0.05$ based on 6 experiments & & & &
\end{tabular}

${ }^{*} p<0.05$ based on 6 experiments

parameters is shown in Table 3. Left ventricular $\mathrm{dP} /$ dt was significantly increased after portacaval shunt (4 days) although left ventricular pressures remained unchanged. Table 3 also shows that these dogs had increased urinary volume following this surgical procedure.

The dogs in the present study resembled earlier studies $^{6}$ maintaining normal glycemia and liver function. The simultaneous increase in plasma insulin and glucagon is likely to contribute to the euglycemic state of these animals. Although it is difficult to explain positive intropic effect of portacaval anastomosis, various gut peptides may directly act on cardiac muscle via systemic circulation and thus provide a basis for systemic diversion of portal blood in various pathophysiological conditions where the functions of the cardiac muscle are compromised. An endogenous diuretic function of the portacaval shunt also can not be ruled out at the present time. These results are interpreted to mean that portacaval shunt can be tested in congestive heart failure requiring diuretics and inotropic agent.

Congestive heart failure is the result of damage to the heart muscle, often triggered by myocardial infarction or high blood pressure. ${ }^{7)}$ The damaged heart muscle is unable to maintain normal blood circulation through the body. The blood flow from the heart is reduced and backs up through the vein causing congestion in the tissues. Although preventing progression of heart failure is one of the main goals in treating this disease, the treatment strategies are now primarily aimed at understanding new concepts in the pathophysiology of heart failure.

It is now believed that the development and progression of heart failure results from the interplay of hemodynamic and neurohumoral mechanisms. ${ }^{8,9}$ While both mechanisms tend to enhance the inotropic state of the heart following an injury to the myocardium, their ability to augment cardiac contractility is reduced in the long run. Although there is little doubt that hemodynamic-neurohormonal models have led to the development of vasodilators, as well as neurohormonal antagonists which are known to be beneficial in the treatment of heart failure, very little attention has been paid to the surgical correction of this disease. In spite of the fact that many more experiments are needed to reach a meaningful conclusion, the present results may indicate the beneficial role of portacaval anastomosis in congestive heart failure.

Acknowledgement The author is grateful in acknowledging the technical assistance of $\mathrm{Mr}$. Mohammad Saleh. Prof. George M. Abouna performed portacaval shunt during his experiments using a liver support machine. 


\section{REFERENCES}

1) Gut peptides: secretion, function and clinical aspects: Proceedings of the Hiroshima Symposium on Gut Hormones, Hiroshima Grand Hotel, July 1719, 1979, Hiroshima, Japan

2) Gehlert, D. R. (1998) Multiple receptors for the pancreatic polypeptide (PP-fold) family: physiological implications. Proc. Soc. Exp. Biol. Med., 218, 722

3) Donest, T., Richwinej, R. T. and Bray, M. S. (1999) Insulin improves functional and metabolic recovery of reperfused working rat heart. Ann. Thorac. Surg., 67, 1682-1688.

4) Abouna, G. M., Ganguly, P. K., Hamdy, H. M., Jabur, S. S., Tweed, W. A. and Costa, G. (1999) Extracorporeal liver perfusion system for successful hepatic support pending liver regeneration or liver transplantation - a preclinical controlled trial. Transplantation, 67, 1576-1583.
5) Iwase, M., Ishikawa, Y., Shen, Y-T., Shannon, R.P., Sato, N., Ganguly, P.K., Eki, T., Vatner, D. E. and Vatner, S. F. (1996) Neurally mediated cardiac effects of forskolin in conscious dogs. Am. J. Physiol., 271, H 1473-H 1482.

6) Waddell, W. R. and Sussman, K. E., (1967) Plasma insulin after diversion of portal and pancreatic venous blood to vena cava. J. Appl. Physiol., 22, 808-812.

7) Ganguly, P. K., Shao, Q., Dhalla, K. S. and Dhalla, N. S. (1997) Differential changes in sympathetic activity in left and right ventricles in congestive heart failure after myocardial infarction. Am. Heart. J., 133, 340-345.

8) Ganguly, P. K. (Ed.) (1991) Catacholamines and heart disease. CRC Press; Boca Raton, FL.

9) Ganguly, P. K. (1989) Catacholamines and cardiovascular disorders: Pathophysiologic considerations. Am. Heart. J., 118, 868-872 